\title{
NOTE ON GIBBS' PHENOMENON
}

BY C. N. MOORE

In my review of the third edition of volume I of Picard's Traité d'Analyse, ${ }^{*}$ I took exception to Picard's claim that Du Bois-Reymond had discovered Gibbs' phenomenon. Concerning the question of priority in this discovery, Professor G. N. Watson has kindly called my attention to an article by $\mathrm{H}$. Wilbraham.t

The phraseology of this paper indicates that Wilbraham was not quite clear in his own mind as to the distinction between the curve which is the limit curve of the approximation curves, $y=S_{n}(x)$, and the curve $y=f(x)$, which represents the limit function. However, his discussion applies to the former curve and furnishes a valid proof of the central features of Gibbs' phenomenon in the case of the particular series he discusses. He also points out that a similar discussion will establish an analogous behavior in the case of another special series. As Professor Watson has said in his letter to me: "It is a remarkable paper for so early a date."

At first thought it seems rather surprising that Wilbraham's paper, dealing with so interesting a property of Fourier's series, should have remained virtually unnoticed for a period of more than half a century, during which the theory of these series was being greatly enlarged. There is, however, a rather natural reason for this, the same reason why Gibbs' paper in NaTuRE at first attracted no general attention. Both Wilbraham and Gibbs restricted their discussion to particular series, and failed to point out that the property in question characterized the behavior of the Fourier's series corresponding to a very broad class of

* This Bulletin, (2), vol. 30 (1924), pp. 554-556.

$\dagger$ Cambridge and Dublin Mathematical Journal, vol 3 (1848), pp. 198-201. 
functions. It was Bôcher's wide generalization* of Gibbs' brief remarks, as well as his lucid exposition of the details of Gibbs' phenomenon, that first aroused general interest in this remarkable property of Fourier's series.

Subsequent to writing the preceding paragraphs I received a letter from Professor H. S. Carslaw, calling my attention to Wilbraham's paper, and I also had the privilege of seeing a copy of the manuscript of Professor Carslaw's historical note, Gibbs' phenomenon in Fourier's series and integrals.t Since this note goes into some detail concerning Du BoisReymond's paper, it seems to me desirable to amplify somewhat my own position regarding this paper, as previously indicated in the review to which reference has been made.

The formulas which Professor Carslaw quotes from Du BoisReymond's paper are the ones to which I referred when I made the statement that "there are certain formulas in the article from which Gibbs' phenomenon might have been deduced". However, if one goes back to page 244 of $\mathrm{Du}$ Bois-Reymond's article, the paragraph beginning at the bottom of this page reveals the fact that he had decided on the basis of physical intuition as to how the approximation curves ought to behave. His analysis seems to have been carried out with a view to substantiating this prejudgment on his part, and that fact in my opinion explains his error as to the behavior of the integral $\int_{0}^{n x}[(\sin \alpha) / \alpha] d \alpha$. If he had examined the behavior of this integral on its own merits, it does not seem likely that he would have made such an error. But the extreme limits $\pm(\pi / 2)$ fitted in with his preconceived ideas, so he apparently jumped to the conclusion that they were correct, having in mind doubtless the relation $\int_{0}^{+\infty}[(\sin \alpha) / \alpha] d \alpha= \pm(\pi / 2)$.

It seems to the writer that Gibbs' phenomenon is most decidedly one of those facts that can only be discovered by the methods of analysis. The approximation curves

* Annals of Mathematics, (2), vol. 7 (1905-06), pp. 123-132.

$\dagger$ See page 419 of the present number of this Bulletin. 
$y=S_{n}(x)$ are obviously continuous curves, and either geometric or physical intuition would naturally suggest that they might behave as Du Bois-Reymond supposed. It is only the more delicate considerations of analysis that would reveal the true facts. That so competent an analyst as $\mathrm{Du}$ Bois-Reymond should have overlooked these facts, when he had formulas before him from which they could readily have been deduced, seems to me all the more reason for not associating his name with the phenomenon in question. It is quite natural and proper to refer to his work in giving the historical background of Gibbs' phenomenon, but in my opinion Professor Picard's designation of the phenomenon as "Phénomène de Du Bois-Reymond et Gibbs" was without adequate justification, even if Wilbraham's article had not existed.

The University of Cincinnati 